\title{
ACESSIBILIDADE EM AMBIENTES VIRTUAIS DE APRENDIZAGEM PARA PESSOAS COM DEFICIÊNCIA VISUAL: PROTOLOCO DE ANÁLISE
}

\author{
Ana Lucia Farão Carneiro de Siqueira, Raquel Rosan Christino Gitahy, Danielle Aparecida \\ Nascimento Santos.
}

Universidade do Oeste Paulista - UNOESTE, Presidente Prudente, SP. E-mail: anasiqueir@unoeste.br.

\section{RESUMO}

Diante dos desafios provocados pelas inovações tecnológicas, o escopo deste artigo consiste em identificar e analisar os recursos necessários para que os Ambientes Virtuais de Aprendizagem (AVA) adotados no desenvolvimento de cursos a distância, possibilitem uma aprendizagem significativa e inclusiva, especialmente, aos estudantes com deficiência visual. O contexto do estudo trata-se de uma instituição de ensino superior pública que oferta cursos na modalidade a distância em nível de graduação e pós-graduação. A abordagem metodológica tem como parâmetros o estudo de caso, cuja base é um curso de especialização implementado no ambiente virtual de aprendizagem utilizado por essa IES. O protocolo de análise gerado busca: a identificação do nível de acessibilidade do ambiente de aprendizagem e recursos disponíveis, bem como a participação e interação com as ferramentas. Para tanto, espera-se observar essa interação em dois sujeitos com deficiência visual. Como resultado espera-se elaborar futuramente parâmetros e indicadores que poderão ser contemplados na criação de ambientes virtuais, visando à melhoria das condições de acessibilidade e interação de cursistas com deficiência visual. Palavras chave: Educação Inclusiva, Acessibilidade, Educação a Distância, Ambiente Virtual de Aprendizagem, Deficiência Visual.

\section{ACCESSIBILITY IN VIRTUAL LEARNING ENVIRONMENTS FOR VISUALLY IMPAIRED PEOPLE: ANALYSIS PROTOCOL}

\footnotetext{
ABSTRACT

In the face of the challenges posed by technological innovations, the scope of this article is to identify and analyze the necessary resources so that the Virtual Learning Environments adopted in the development of distance learning courses, allow a meaningful and inclusive learning, especially for visually impaired students. The context of this study is a public higher education institution, which offers courses in the distance learning modality in graduate and postgraduate levels. The methodological approach has as parameters the case study, which base is a specialization course implemented in the virtual learning environment used by this institution. The generated analysis protocol seeks to: identify the accessibility level of the learning environment and available resources, as well as participation and interaction with the tools. For this purpose, it will be observed the interaction of two individuals with visual impairment. As a result it is expected the preparation, in the future, of parameters and indicators that might be considered in the creation of virtual environments in order to improve the accessibility and interaction conditions of course participants with visual impairment.

Keywords: Inclusive Education, Accessibility, Distance Education, Virtual Learning Environment, Visual Impairment.
} 


\section{INTRODUÇÃO}

Os crescentes desafios provocados pelas inovações tecnológicas no ensino, especialmente, para os Estudantes Público-Alvo da Educação Especial com Deficiência Visual (EPAEE) ${ }^{1}$ tem sido amplamente discutido pela academia nos últimos anos, no Brasil. Cada vez mais as pessoas com deficiência têm acesso aos meios tecnológicos e à internet, não limitando-se mais às questões geográficas para a busca de novos conhecimentos. Surge a necessidade de adequar uma nova realidade, em que os recursos tecnológicos digitais sejam utilizados nos processos de ensino e da aprendizagem, garantindo uma educação acessível a todos.

Pesquisas realizadas na área de Educação a Distância $(E a D)^{2}$, revelam que essa modalidade tem uma crescente e significativa importância na maneira de ensinar e de aprender dos brasileiros.

Segundo o Instituto Nacional de Estudos e Pesquisas Educacionais Anísio Teixeira - INEP (BRASIL, 2015 p.18)

Embora a educação a distância corresponda a uma pequena parcela do total de cursos de graduação, ela atingiu o maior percentual de crescimento, 35,3\%, considerando o período de 2010 a 2013, indicando que está fazendo, cada vez mais, parte do cotidiano brasileiro. As novas mídias e as novas formas de interação entre aluno e docente na chamada economia do conhecimento fizeram com que os cursos ofertados nessa modalidade saltassem para 1.258 no ano de $2013^{3}$.

Outro dado interessante apontado pelo Censo refere-se à evolução das matrículas nas graduações a distância com crescimento de $24 \%$ em relação a modalidade presencial que foi de 12,4\% (BRASIL, 2015, p.22)

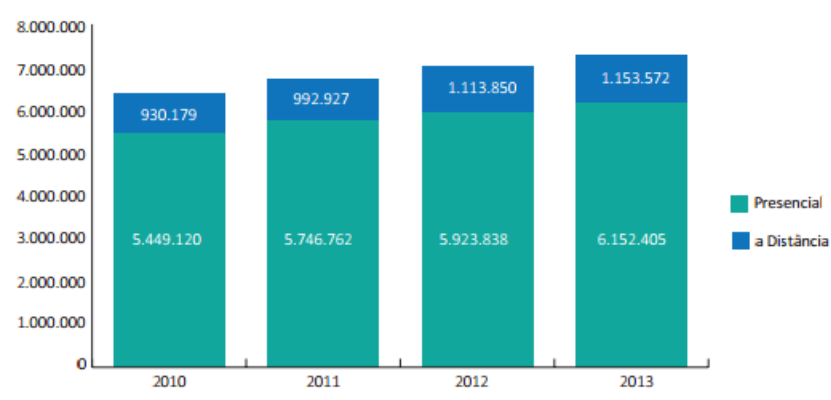

Gráfico INEP Censo 2015 p. 22

A utilização de recursos que possibilitem uma nova realidade social de inclusão e respeito, trazem uma perspectiva de uma forma consciente e importante de inserir de forma literal as pessoas com deficiência em um mundo para e por videntes, mudando a postura de olhar, entender e de relacionar-se com esses indivíduos (COSTA, LOZANO, 2013, p. 909).

Segundo dados do IBGE de $2010^{4}$, entre as deficiências investigadas, a deficiência visual é $18,8 \%$ da população e é a deficiência de maior incidência.

Nesse sentido, é fato que as instituições educacionais, nos diferentes níveis de ensino, devem ampliar as formas de acesso e permanência, acolhendo a todos, atentando-se inclusive para os cursos oferecidos na modalidade a distância. Modalidade essa que, para muitos desses estudantes, torna-se uma oportunidade ímpar para o acesso a processos formativos. Nesse

\footnotetext{
${ }^{1}$ EPAEE, segundo a Política Nacional de Educação Especial na Perspectiva da Educação Inclusiva (2007), são estudantes com deficiência (Auditiva Física, Intelectual e Visual), transtornos globais de desenvolvimento e altas habilidades/superdotação.

${ }^{2}$ (OLIVEIRA, SILVA, 2015), (CAMPOS, MENDES, 2015).

${ }^{3}$ Resumo Técnico Censo da Educação Superior 2013 disponível em

http://download.inep.gov.br/download/superior/censo/2013/resumo tecnico_censo_educacao superior 2013.pdf Acessado em março/2016

${ }^{4}$ http://www.ibge.gov.br/home/presidencia/noticias/imprensa/ppts/00000008473104122012315727483985.pdf. Acesso em abril/2016
} 
cenário, as Instituições de Ensino Superior (IES) carecem de um processo de mudança organizacional que reflita nas questões práticas de gestão e nas relações internas e externas.

O Artigo 19 da Declaração Universal dos Direitos Humanos ${ }^{5}$ afirma:

Todo ser humano tem direito à liberdade de opinião e expressão; este direito inclui a liberdade de, sem interferência, ter opiniões e de procurar, receber e transmitir informações e ideias por quaisquer meios e independentemente de fronteiras.

Segundo levantamento divulgado em agosto de 2015 pelo Instituto Brasileiro de Geografia e Estatística (IBGE) junto com o Ministério da Saúde aponta que 6,2\% da população brasileira têm alguma deficiência. Quatro tipos de deficiência foram considerados pela Pesquisa Nacional de Saúde (PNS): auditiva, visual, física e intelectual. A pesquisa revela ainda que a deficiência visual é a mais representativa e atinge $3,6 \%$ dos brasileiros. "O grau intenso ou muito intenso da limitação impossibilita $16 \%$ dos deficientes visuais de realizarem atividades habituais como ir à escola, trabalhar e brincar" (EBC, 2015).

No Decreto No. 5.296, Art.70, item III (2004), entende-se por Deficiência Visual: cegueira, na qual a acuidade visual é igual ou menor que 0,05 no melhor olho, com a melhor correção óptica; a baixa visão, que significa acuidade visual entre 0,3 e 0,05 no melhor olho, com a melhor correção óptica; os casos nos quais a somatória da medida do campo visual em ambos os olhos for igual o menor que $60^{\circ}$; ou a ocorrência simultânea de quaisquer das condições anteriores ${ }^{6}$.

Com base nesses dados, evidencia-se a necessidade de criar meios para que seja dada a oportunidade de que as pessoas com deficiência possam desenvolver as suas potencialidades, realizando processos formativos no meio digital.

Assim, tendo em vista a necessidade em analisar as necessidades dos EPAEE com deficiência visual, diante da participação em processos formativos realizados em Ambientes Virtuais de Aprendizagem (AVA), o desenvolvimento deste artigo será norteado pelos seguintes questionamentos: Como vem sendo oportunizado o acesso dos Estudantes Público-Alvo da Educação Especial (EPAEE) com deficiência visual, em processos formativos desencadeados em ambientes virtuais de aprendizagem? Que recursos de acessibilidade seriam importantes para se oferecer melhores condições para o seu acesso em cursos ofertados na modalidade a distância?

Espera-se, mediante a busca em responder essas questões norteadoras, oferecer parâmetros de acessibilidade à informação e ao conhecimento, permitindo sua participação efetiva de pessoas com deficiência visual em cursos na modalidade a distância.

\section{Acessibilidade Digital em Ambientes Virtuais de Aprendizagem}

A Constituição Federal (Brasil, 1988) ${ }^{7}$ no art 1ㅇ, inc. II e III garante a cidadania e a dignidade da pessoa humana, e como um dos seus objetivos fundamentais a promoção do bem de todos, sem preconceitos de origem, raça, sexo, cor, idade e quaisquer outras formas de discriminação, conforme art 30, inc. IV. A lei ainda garante o direito de igualdade no art 50 e nos artigos 205 e seguintes o direito de todos à educação visando "pleno desenvolvimento da pessoa, seu preparo para o exercício da cidadania e sua qualificação para o trabalho".

Além disso, no art. 206, inc. I declara "igualdade de condições de acesso e permanência na escola". Portanto a Constituição Federal garante o direito à educação e ao acesso à escola a todos, não podendo ficar ausente nenhuma escola reconhecida pelos órgãos oficiais.

\footnotetext{
${ }^{5}$ Disponível em: http://unesdoc.unesco.org/images/0013/001394/139423por.pdf - NAÇÕES UNIDAS. New York: ONU, 1948. Acesso jan/2016

${ }^{6} \mathrm{http} / / /$ www.planalto.gov.br/ccivil 03/_ato2004-2006/2004/decreto/d5296.htm . Acesso em fev/2016

7 http://www.planalto.gov.br/ccivil 03/Constituicao/Constituicao.htm. Acesso jan/2016
} 
O Plano Nacional de Educação de 2010 estabelecido para o decênio 2011-2020 declara na Meta 12.10 "Assegurar condições de acessibilidade nas instituições de educação superior, na forma da legislação". 8

De acordo com a Lei no 13.146, de 6 de julho de 2015 (BRASIL, 2015) considera-se acessibilidade:

I - acessibilidade: condição para utilização, com segurança e autonomia, total ou assistida, dos espaços, mobiliários e equipamentos urbanos, as edificações, dos serviços de transportes e dos dispositivos, sistemas e meios de comunicação e informação, por pessoa portadora de deficiência ou com mobilidade reduzida; (BRASIL, 2015, s/p).

No artigo Art. $3^{\circ}$ cláusula IV da lei em referência, uma das barreiras que o documento se refere ao dizer qualquer "entrave ou obstáculo que impossibilitam as pessoas de se comunicarem ou terem acesso à informação", está se referindo as barreiras existente que dificultem ou impossibilitam o acesso a comunicação e informação.

O acesso a comunicação e informação se faz através do Ambiente Virtual de aprendizagem (AVA) que segundo o Ministério de Educação da Secretaria de Educação a Distância ${ }^{9}$, o AVA é um ambiente computacional, especialmente implementado para atendimento às necessidades do estudante. $\mathrm{O}$ ambiente deve fornecer suporte a qualquer atividade a ser realizada com um conjunto de ferramentas utilizadas no processo de aprendizagem

Encontramos ainda na Lei $n=13.146$, no Art. 3ํa informação do desenho universal que visa o acesso autônomo, seguro e confortável a pessoa com qualquer tipo de deficiência:

II desenho universal: concepção de produtos, ambientes, programas e serviços a serem usados por todas as pessoas, sem necessidade de adaptação ou de projeto específico, incluindo os recursos de tecnologia assistiva. (BRASIL, 2015, s/p)

Segundo Moran (2012) determinadas páginas da internet dificultam o acesso de pessoas com deficiência e devem ser alteradas para atender aos padrões internacionais de acessibilidade.

A organização da tecnologia em favor de maior igualdade, inclusão e acesso não está absolutamente garantida, mas dependerá, em grande medida, da mobilização de alunos, educadores e comunidades, exigindo que a tecnologia seja usada de maneira que atenda aos interesses da educação (Moran, 2012, p.97)

Com o uso da Tecnologia Digital de Informação e Comunicação (TDIC), Valente cita ainda a "Teoria da distância transacional" de Moore (1993)

que estabelece uma relação entre a estrutura dos programas educacionais, a interação entre os aluno e professores e a natureza e o grau de autonomia do aluno. Segundo essa teoria, quanto maior for o diálogo, mais flexível for a estrutura de um curso, mais autonomia tiver o aluno, menor a distância transacional. (VALENTE, 2011, p.16)

A análise de Moore revela a necessidade de atendimento aos parâmetros do desenho universal para os cursos de $\mathrm{EaD}$, de maneira que pessoas com qualquer deficiência visual possa ter acesso seguro e de qualidade para desenvolver competências construídas na interação com a informação que deve ser acessada.

\footnotetext{
${ }^{8}$ http://portal.mec.gov.br/index.php?option=com docman\&view=download\&alias=7116-pl-pne-2011-2020\&ltemid=30192. Acesso em fev/2016.

9 Referenciais De Qualidade Para Educação Superior a Distância. http://portal.mec.gov.br/seed/arquivos/pdf/legislacao/refead1.pdf Acesso em $\mathrm{fev} / 2016$
} 


\section{PROCEDIMENTOS METODOLÓGICOS}

O presente estudo adota um enfoque qualitativo, sendo desencadeado a partir de um estudo de caso. A respeito da pesquisa qualitativa, Santos Filho (2007, p. 43) afirma que "seu propósito fundamental é a compreensão, explanação e especificação do fenômeno. O pesquisador precisa tentar compreender o significado que os outros dão às suas próprias situações".

Nesse contexto, foi adotado para análise o ambiente virtual de aprendizagem utilizado por uma instituição de ensino superior pública, localizada no estado de São Paulo/SP que oferta cursos na modalidade a distância desde 2009.

Além da análise desse AVA, com o propósito de enriquecimento dos dados e análises realizadas, bem como da identificação do nível de acessibilidade do ambiente de aprendizagem e recursos disponíveis tem sido considerada na pesquisa a participação de dois sujeitos, ou seja, de dois EPAEE com deficiência visual.

Foram convidadas, uma pessoa com cegueira e uma com baixa visão, que residem em Presidente Prudente/SP. Esses sujeitos tem o papel de acessar e interagir com os recursos de um curso de especialização ofertado pela IES na modalidade de Educação a Distância. O critério para seleção dos sujeitos foi o não envolvimento com o ambiente ou curso a ser analisado.

\section{RESULTADOS PRELIMINARES: O PROTOCOLO DE ANÁLISE}

A coleta de dados da pesquisa será realizada considerando os seguintes instrumentos: observação e entrevista semiestruturada.

A coleta de dados no ambiente virtual dar-se-á a partir da observação do pesquisador, que uma vez inserido no ambiente de aprendizagem, lançará seu olhar para seus recursos e materiais midiáticos disponíveis. Na pesquisa será utilizada a observação sistemática também chamada de "observação planejada" ou "controlada" que tem como característica ser estruturadas e realizada em condições controladas, tendo os objetivos e propósitos predefinidos. "Utiliza normalmente um instrumento adequado para sua efetivação, além de indicar e delimitar a área a ser observada, requerendo um planejamento prévio para seu desenvolvimento". (BARROS, 2007, p.74).

A entrevista semiestruturada será realizada junto aos sujeitos da pesquisa, aplicadas pelo próprio pesquisador durante encontros agendados com os participantes. No momento de sua realização o pesquisador utilizará recursos para registrar as falas e outras manifestações que surgirem nesse instante. Demo (2013, p. 120) observa que é preferível a entrevista orientada por um roteiro que contempla, entre outros aspectos, as seguintes questões: Como é o acesso ao AVA?; Quais são as facilidades ou dificuldades de acesso?; Dificuldades em utilizar leitores de tela?; Quais recursos disponíveis no ambiente virtual de aprendizagem adotado no curso?; Como é a navegabilidade? Há alguma ferramenta com dificuldade de utilização? Por quê?; Quais são as dificuldades encontradas quanto à exploração dos materiais disponíveis? Quais são as maiores dificuldades para o uso do AVA e quais as estratégias adotadas para a superação?.

Durante a aplicação do protocolo, o pesquisador não só irá perguntar, mas também observar, participando ativamente, no sentido de testar as respostas, aprofundar os tópicos, sentir a subjetividade, propiciando com que a emoção das pessoas aos responderem às questões se manifeste.

\section{CONSIDERAÇÕES FINAIS}

Com base no protocolo de análise do Ambiente Virtual de Aprendizagem, a partir das observação e entrevistas, espera-se identificar quais são os recursos que tornam um ambiente virtual de aprendizagem acessível para pessoas com deficiência visual e quais mudanças as Instituições de Ensino Superior (IES) devem desencadear para adequar o atendimento ofertado, considerando, em especial, os estudantes com deficiência visual. 
Apenas a introdução das TDIC não garante um ensino de boa qualidade, faz-se necessário que as IES construam um projeto que incorpore ações estratégicas de planejamento administrativo e pedagógico para atender a demanda desses estudantes para que conquistem um grau de autonomia e aprendizagem significativa e com qualidade.

\section{REFERÊNCIAS}

BARROS, Aidil J. da S., LEHFELD, Neide A.de Souza, Fundamentos de metodologia científica. 3.ed. São Paulo: Pearson Prentice Hall, 2007.

BRASIL, Decreto n. 5296, de 2 de dezembro de 2004. Diário Oficial da União. Brasília, DF, 3 de dez. 2004. Disponível em: http://goo.gl/FJMk9. Acesso em fevereiro/2016.

BRASIL. Censo da educação superior 2013: resumo técnico. - Brasília: Instituto Nacional de Estudos e Pesquisas Educacionais Anísio Teixeira, 2015. Disponível em http://download.inep.gov.br/download/superior/censo/2013/resumo tecnico censo educacao s uperior 2013.pdf. Acesso em março/2016

CAMPOS, Mariana de Lima I.L., MENDES, Enicéia G. FORMAÇÃOdE PROFESSORES PARA A EDUCAÇÃO INCLUSIVA EM CURSOS À DISTÂNCIA: UM ESTUDO DE CAMPO DOCUMENTAL. Revista Cocar. Belém/Pará, Edição Especial, N.1, p. 209-227 | jan-jul 2015. http://paginas.uepa.br/seer/index.php/cocar/article/view/625/513. Acesso em junho de 2016

COSTA, Maria Luisa Furlan, LOZANO, Taissa Vieira. Educação a Distância e Deficiência Visual: Possibilidades e Perspectivas. Atos de Pesquisa em Educação - PPGE/ME, ISSN 1809-0354 v.8,n.3, p.901-920, set/dez. 2013. Disponível em < http://proxy.furb.br/ojs/index.php/ atosdepesquisa/article/viewFile/3431/2482>. Acesso em maio 2014.

DEMO, Pedro. Metodologia da investigação em educação [livro eletrônico]/Pedro Demo. Curitiba:InterSaberes, 2013.

MORAN, José Manuel. A educação que desejamos: Novos desafios e como chegar lá. Campinas, SP: Papirus, 2012.

OLIVEIRA, Ana Emília, SILVA, Everaldo da. A educação a distância e a sua contribuição na inclusão social. Cadernos Zygmunt Bauman. V.5, n.10, p.10-18, 2015. http://www.periodicoseletronicos.ufma.br/index.php/bauman/issue/view/296/showToc. Acesso em maio 2016

SANTOS FILHO, J. C. dos S.; GAMBOA, S. S. Pesquisa educacional: quantidade-qualidade. 6. ed. São Paulo: Cortez, 2007.

VALENTE, José Armando. Educação a distância: pontos e contrapontos. José Armando Valente, José Manuel Moran; Valéria Amorim Arantes (organizadora). São Paulo: Summus 2011. 